\title{
The effect of substrate texture on colonization by stream macroin- vertebrates
}

\author{
L. Boyero
}

Museo Nacional de Ciencias Naturales (CSIC). José Gutiérrez Abascal 2, 28006. Madrid, Spain. Current address: School of Tropical Biology, James Cook University, Townsville, Qld 4811, Australia. E-mail: luz.boyero@jcu.edu.au

The effect of substrate texture on colonization by stream macroinvertebrates was studied in a mountain stream. Experimental patches made of natural substrate, with two levels of cobble and gravel texture (rough and smooth), were subjected to two colonization periods (two hours and one week) within a riffle. Cobble texture affected the number of individuals and taxa colonizing substrate patches, although these relationships depended on time of colonization and some local environmental factors. Texture influence was different for different taxa, and only affected the scraper functional feeding group after one week of colonization, probably in relation to the development of an epilithic layer. These results suggest a significant effect of the surface texture of substrate on colonization by macroinvertebrates, although the effect is complex and needs more careful examination.

Keywords : Patches, spatial heterogeneity, colonization, stones, gravel, macroinvertebrates.

\section{Introduction}

Habitat heterogeneity is a major feature in stream ecosystems at a wide range of spatial scales (Cooper et al. 1997). However, its effect on macroinvertebrate communities is known only at certain scales, mostly that of mesohabitat (e.g. bedrock versus cobble-boulder riffles; Robson \& Barmuta 1998), while it remains almost unknown at small scales (individual substrate patches or individual substrate particles) because opposing results have been found (Vinson \& Hawkins 1998).

The architecture of the physical habitat is likely to affect the structure of macroinvertebrate communities at spatial scales similar to their body length (Robson \& Barmuta 1998). At these scales, one type of habitat architecture is the texture of substrate particles, that is, the degree of roughness of the surface to which macroinvertebrates attach. Rough surfaces are viewed as a better habitat for macroinvertebrates than smooth surfaces, given that rough surfaces may provide pits and grooves that are used by individuals as a refuge from predators (Downes \& Jordan 1993). Moreover, surface texture can be responsible for the degree of de- velopment of an epilithic layer, which serves as food for many species, and it seems that epilithon grows more abundantly on rough than on smooth surfaces (Sanson et al. 1995), so these surfaces may harbor a higher number of grazers. However, smooth substrates may also provide some advantages. For example, a smooth surface is preferred by animals that use suckers or other structures to get «glued» to the substrate (e.g. simuliids, Mackay 1992).

Although the importance of substrate texture to macroinvertebrate communities has been recognized for a long time (Minshall 1984), it has been poorly examined, and the existing evidence mainly comes from experiments performed using artificial substrates (e.g. Gawne \& Lake 1995, Way et al. 1995, Robson \& Barmuta 1998). Thus, it is unclear if manipulated surfaces realistically mimic the complexity of natural surfaces (Downes et al. 2000). Very little evidence exists that roughness of natural substrates affects macroinvertebrate abundance and taxa richness, but it seems that granodiorites and crystal-rich volcanic rocks (roughtextured) contain more individuals and taxa than crystal-poor volcanic rocks, siltstones and sandstones (smooth-textured; Downes et al. 2000). 
In this study, the effect of surface roughness of natural substrate particles (cobbles and gravel) on macroinvertebrate communities colonizing substrate patches was examined. An experiment was designed to test the following hypotheses: 1) surface texture of natural substrate particles affects colonization by macroinvertebrates; and 2) this relationship depends on time of colonization.

\section{Materials and methods}

\section{Study site}

The experiment was conducted in June-July 2001 at Peñalara stream, which is located in Peñalara Natural Park, Central Spain (Fig. 1). This Park protects a high altitude area of glacier origin, which includes many narrow and shallow streams that belong to the Lozoya River basin. The vegetation of Peñalara Natural Park consists of alpine meadows with sparse Cytisus scopa rius (L.) Link, and Juniperus communis L., and Pinus sylvestris L. below $1900 \mathrm{~m}$. The study stream is a first order stream with headwaters at $2100 \mathrm{~m}$ above sea level. The glacier geomorphology is responsible for abrupt changes in slope in this stream, which alternates between very steep and flat reaches. The study area was a $70 \mathrm{~m}$ long riffle within a flat reach, which drained an alpine meadow area. Substrate was composed mainly of cobbles surrounded by gravel and sand. The geologic nature of the area, made of Paleozoic igneous bedrock, makes the water slightly acid ( $\mathrm{pH} 5.5$ - 6; measured with $\mathrm{pH}$ strips), and is responsible for the predominantly granitic nature of the stream substrate. However, about $5 \%$ of the substrate in the study stream is composed by quartzite particles. During the study, the riffle had a mean stream width of $1.2 \mathrm{~m}$; water depth and current velocity were $10.4 \pm 0.8 \mathrm{~cm}$ and $13.5 \pm 0.7 \mathrm{cms}-1$ (mean $\pm \mathrm{SE})$, respectively; and mean water temperature was $18.5^{\circ} \mathrm{C}$.

\section{Experimental design}

Two levels of surface texture were available from natural cobbles and gravel in the study stream: rough (granite) and smooth (quartzite). All cobbles and gravel were taken from a temporally dry stream channel close to the study stream, so they were completely free of attached epilithon. Cobble size ranged from 10 to 16 $\mathrm{cm}$ (major axis), and gravel size from 1 to $5 \mathrm{~cm}$ (major axis).

Experimental substrate patches consisted of a plastic square base $(15 \times 15 \mathrm{~cm})$, which was completely covered by a layer of sand grains (glued to the plastic). Two cobbles and some surrounding gravel were placed above the sand layer (see Fig. 1), thus simulating the natural conditions in the stream (cobbles and gravel laying above a sandy bottom). There were nine diff e $\mathrm{r}$ e $\mathrm{n} t$ patch types, which resulted from combining three types of cobble texture (only rough cobbles, only smooth cobbles, or both rough and smooth cobbles) and three types of gravel texture (only rough gravel, only smooth gravel, or both rough and smooth gravel). Each patch type had five replicates, so there were a total of 45 patches, which were randomly placed on the streambed.

\section{Field methods}

The experiment was performed in two stages: 1) two hours and 2) one week. Patches were first left on the streambed to be colonized for two hours. After that, they were sampled with a modified Surber sampler, with an exterior side of $15 \mathrm{~cm}$. Lateral sides of the sampler were made of solid plastic, and the side facing current was a panel of $0.125 \mathrm{~mm}$ mesh net, to avoid contamination of the sample with substrate or macroinvertebrates from outside. The downstream side had a $0.125 \mathrm{~mm}$ mesh net with a sample bottle attached. The substrate was disturbed by hand and stones were washed and rubbed to dislodge attached macroinvertebrates, which fell into the net with the help of the current. Stones and gravel were brushed and dried, and patches were returned to the same locations on the streambed, where they were left to be colonized for one week. Finally, patches were sampled again as described above.

At each substrate patch, the following environmental factors were recorded: current velocity, measured with an Owens River Hydroprop (Great Atlantic, UK) flowmeter at $5 \mathrm{~cm}$ above the streambed (at each of the two sampling times); water depth, measured with a meter ruler; and total cobble surface area, calculated as the sum of the surface area of the two cobbles in the patch, which was estimated by foil wrapping (following Doeg \& Lake 1981).

\section{Laboratory methods and statistical analysis}

All the samples were preserved in $4 \%$ formaldehyde in the field, and carried to the laboratory, where macroinvertebrates were sorted and identified using a dissecting microscope. Body size of all individuals was measured with a precision of $0.5 \mathrm{~mm}$. Each taxon was assigned to one of the five functional feeding groups (scrapers, shredders, gatherers, filterers, and predators, sensu Wallace \& Webster 1996), according to Merritt $\&$ Cummins (1996) and Tachet et al. (2002). 


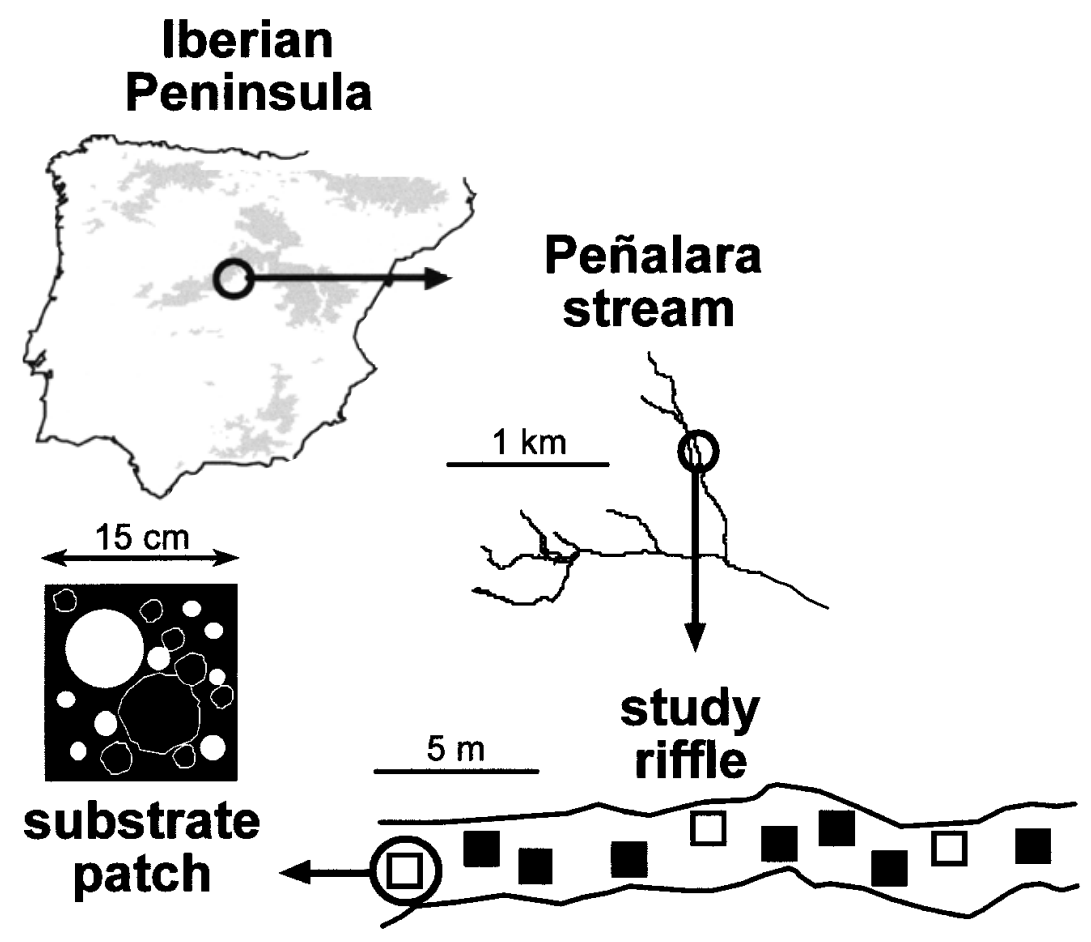

Fig. 1. Location of Peñalara stream on the Iberian Peninsula, and the study riffle in Peñalara stream. The substrate patches in the study riffle (simplified : different patterns represent different combinations of cobble and gravel texture), and experimental cobbles and gravel in a substrate patch (simplified : white circles represent smooth texture, and black circles represent rough texture) are also depicted.

The variables used to describe macroinvertebrate communities in patches were: 1) abundance (number of individuals per patch); 2) taxa richness (number of taxa per patch); 3 ) mean body size (average of body size of all the individuals in the patch); 4) community evenness (Magurran 1988); 5) abundances of the most common taxa (Baetis, Leptophlebiidae, Leuctra, Orthocladiinae, and Tanypodinae); and 6) relative abundance (percentage of the total number of individuals) of each functional feeding group. These variables were log-transformed for subsequent analyses, in order to fit a normal distribution.

A repeated-measures ANCOVA was used to test the e ffect of substrate texture, time of colonization, and the interactions of these factors with the measured environmental variables, on patch colonization (abundance, richness, body size, evenness, abundances of the most common taxa, and relative abundance of each functional feeding group in patches). Cobble texture and gravel texture were between-subjects factors with three levels (rough; smooth; rough and smooth); time of colonization was a within-subjects or repeated measures factor with two levels (two hours; one week); the environmental factors were included in the model as continuous predictors or covariates.

\section{Results}

A total of 35 taxa was found in substrate patches, of which only 22 were present within two hours of colonization, while 31 were present within one week of colonization (see Table 1). Taxa that were absent within two hours but present within one week were Rhithro gena, Rhyacophilidae, Hydropsychidae, Lepidostomatidae, Polycentropodidae, Limnius, Hydraena, Chironominae, Simuliidae, Ge rris, Velia, Notonecta, and Tricladida. Taxa present within two hours but absent within one week were Tipulidae, Ceratopogonidae, Dolichopodidae, and Micronecta. Within two hours of colonization, only $23 \%$ of the taxa were relatively common (present in more than $10 \%$ of patches), while within one week of colonization, $61 \%$ of the taxa 
were relatively common. Baetis clearly dominated substrate patches within two hours (comprising $55 \%$ of the total number of individuals, and present in the $87 \%$ of substrate patches). However, within one week, there was no numerically dominant taxon, although some taxa were present in a high proportion of substrate patches (100\% in the case of Orthocladiinae; see Table $1)$.

Table 1. Taxonomic groups found at each time of colonization; relative frequency (percentage of samples at which each taxon is present) and relative abundance of each taxon (percentage of total individuals) are indicated.

\begin{tabular}{|c|c|c|c|c|}
\hline & \multicolumn{2}{|c|}{2 hours } & \multicolumn{2}{|c|}{1 week } \\
\hline & \%samples & \%indiv. & \%samples & \%indix: \\
\hline \multicolumn{5}{|c|}{ EPHEMEROPTERA } \\
\hline Baetis & 87 & 55 & 93 & 12 \\
\hline Ecdyonurus & 13 & 3 & 56 & 7 \\
\hline Epeorus & 4 & 1 & 4 & 1 \\
\hline Rhithrogena & 0 & 0 & 11 & 1 \\
\hline Leptophlebiidae & 9 & 3 & 78 & 10 \\
\hline Ephemerella & 4 & 1 & 58 & 7 \\
\hline \multicolumn{5}{|l|}{ PLECOPTERA } \\
\hline Dinocras & 7 & 1 & 13 & 2 \\
\hline Leuctra & 13 & 3 & 69 & 8 \\
\hline Protonemura & 4 & 1 & 2 & 0 \\
\hline \multicolumn{5}{|l|}{ TRICHOPTERA } \\
\hline Limnephilinae & 24 & 7 & 40 & 5 \\
\hline Rhyacophilidae & 0 & 0 & 4 & 1 \\
\hline Hydropsychidae & 0 & 0 & 2 & 0 \\
\hline Lepidostomatidae & 0 & 0 & 11 & 1 \\
\hline Sericostomatidae & 2 & 0 & 11 & 1 \\
\hline Polycentropodidae & 0 & 0 & 2 & 0 \\
\hline \multicolumn{5}{|l|}{ COLEOPTERA } \\
\hline Oulimnius & 4 & 1 & 24 & 3 \\
\hline Elmis & 2 & 0 & 11 & 1 \\
\hline Limnius & 0 & 0 & 4 & 1 \\
\hline Hydraena & 0 & 0 & 2 & 0 \\
\hline Dytiscidae & 9 & 3 & 18 & 2 \\
\hline \multicolumn{5}{|l|}{ DIPTERA } \\
\hline Orthocladiinae & 40 & 12 & 100 & 12 \\
\hline Tanypodinae & 9 & 4 & 80 & 10 \\
\hline Chironominae & 0 & 0 & 33 & 4 \\
\hline Simuliidae & 0 & 0 & 13 & 2 \\
\hline Tipulidae & 2 & 0 & 0 & 0 \\
\hline Ceratopogonidae & 2 & 0 & 0 & 0 \\
\hline Dolichopodidae & 2 & 0 & 0 & 0 \\
\hline \multicolumn{5}{|l|}{ HETEROPTERA } \\
\hline Gerris & 0 & 0 & 4 & 1 \\
\hline Velia & 0 & 0 & 2 & 0 \\
\hline Notonecta & 0 & 0 & 18 & 2 \\
\hline Micronecta & 4 & 2 & 0 & 0 \\
\hline \multicolumn{5}{|l|}{ NON-INSECTS } \\
\hline Hydracarina & 4 & 1 & 7 & 1 \\
\hline Turbellaria & 0 & 0 & 2 & 0 \\
\hline Gastropoda & 4 & 1 & 9 & 1 \\
\hline Oligochaeta & 4 & 1 & 31 & 4 \\
\hline
\end{tabular}

The range values of the measured environmental variables (current velocity at each of the two sampling times, water depth, and total cobble surface area) for each patch type are summarized in Table 2.

The effect of cobble texture on macroinvertebrate abundance was marginally significant $\left(\mathrm{F}_{2,16}=3.40\right.$, $\mathrm{p}=0.0588$ ). Additionally, abundance was affected by cobble surface area $\left(\mathrm{F}_{1,16}=6.35, \mathrm{p}=0.0227\right)$, and the following interactions were significant : cobble texture $\mathrm{x}$ gravel texture $\left(\mathrm{F}_{4,16}=3.11, \mathrm{p}=0.0451\right)$, cobble texture $x$ cobble surface area $\left(\mathrm{F}_{2,16}=6.62, \mathrm{p}=0.0080\right)$, cobble texture $\mathrm{x}$ current velocity at the first and the second sampling moments $\left(\mathrm{F}_{2,16}=3.40, \mathrm{p}=0.0588\right.$ and $\mathrm{F}_{2,16}=5.62, \mathrm{p}=0.0142$, respectively), and time of colonization $\mathrm{x}$ cobble texture $\mathrm{x}$ current velocity at the first and the second sampling moments $\left(\mathrm{F}_{2,16}=6.27\right.$, $\mathrm{p}=0.0098$ and $\mathrm{F}_{2,16}=5.39, \mathrm{p}=0.0162$, respectively). In general, abundance seemed to be higher for patches with rough cobbles after two hours, but the opposite occurred after one week (Fig. 2).

For taxa richness, the significant effects were cobble surface area $\left(\mathrm{F}_{1,16}=4.50, \mathrm{p}=0.049\right)$, current velocity at the second sampling moment $\left(\mathrm{F}_{1,16}=5.13\right.$, $\mathrm{p}=0.037$ ), and the following interactions: time of colonization $\mathrm{x}$ gravel texture $\mathrm{x}$ current velocity at the first sampling moment $\left(\mathrm{F}_{2.16}=3.89, \mathrm{p}=0.0419\right)$, and time of colonization $\mathrm{x}$ cobble texture $\mathrm{x}$ current velocity at the second sampling moment $\left(\mathrm{F}_{2,16}=6.49\right.$, $\mathrm{p}=0.0086$ ). As for abundance, patches with rough cobbles contained higher taxa richness after two hours, but not after one week (Fig. 2).

Mean body size of individuals was affected by the interaction gravel texture $\mathrm{x}$ current velocity at both

Table 2. Range values of the measured environmental variables (current velocity at the first and second sampling times, water depth, and total stone area) for each patch type ( $\mathrm{R}$ : rough texture; $\mathrm{S}$ : smooth texture).

\begin{tabular}{cccccc}
\hline $\begin{array}{c}\text { Stone } \\
\text { texture }\end{array}$ & $\begin{array}{c}\text { Gravel } \\
\text { texture }\end{array}$ & $\begin{array}{c}\text { Velocity 1 } \\
(\mathbf{c m} / \mathbf{s})\end{array}$ & $\begin{array}{c}\text { Velocity 2 } \\
(\mathbf{c m} / \mathbf{s})\end{array}$ & $\begin{array}{c}\text { Depth } \\
(\mathbf{c m})\end{array}$ & $\begin{array}{c}\text { Area } \\
\left(\mathbf{c m}^{2}\right)\end{array}$ \\
\hline R \& S & R \& S & $8-22$ & $7-13$ & $8-10$ & $716-980$ \\
R \& S & S & $7-25$ & $7-18$ & $6-11$ & $613-883$ \\
R\& S & R & $7-22$ & $7-19$ & $6-11$ & $767-916$ \\
S & R \& S & $7-19$ & $7-12$ & $6-13$ & $651-816$ \\
S & S & $9-20$ & $7-21$ & $7-11$ & $568-822$ \\
S & R & $11-19$ & $7-19$ & $7-12$ & $802-980$ \\
R & R \& S & $10-28$ & $7-39$ & $6-12$ & $748-984$ \\
R & S & $7-16$ & $7-21$ & $6-16$ & $732-1126$ \\
R & R & $7-33$ & $11-21$ & $9-17$ & $831-1252$ \\
\hline
\end{tabular}


sampling moments $\left(\mathrm{F}_{2,16}=3.76, \mathrm{p}=0.0459\right.$ and $F_{2,16}=9.79, p=0.0017$ for the first and second sampling moment, respectively), and time of colonization $\mathrm{x}$ gravel texture $\mathrm{x}$ current velocity at the second sampling moment $\left(\mathrm{F}_{2,16}=4.93, \mathrm{p}=0.0215\right)$. After one week, mean body size seems to be lower in patches with rough gravel (Fig. 2).

Evenness was affected by water depth $\left(\mathrm{F}_{1,16}=6.29\right.$, $p=0.0233)$, and the following interactions were significant : cobble texture $\mathrm{x}$ cobble surface area $\left(\mathrm{F}_{2,16}=3.87, \mathrm{p}=0.0425\right)$, cobble texture $\mathrm{x}$ current velocity at the second sampling moment $\left(\mathrm{F}_{2,16}=5.10\right.$, $\mathrm{p}=0.0194)$, time of colonization $\mathrm{x}$ water depth $\left(F_{1,16}=4.74, p=0.0448\right)$, time of colonization $x$ cobble texture $x$ cobble surface area $\left(F_{2,16}=4.61\right.$, $\mathrm{p}=0.0263$ ), and time of colonization $\mathrm{x}$ cobble texture $\mathrm{x}$ current velocity at the second sampling moment $\left(\mathrm{F}_{2,16}=3.84, \mathrm{p}=0.0435\right)$. As for abundance and richness, evenness seems to be higher in patches with only rough cobbles after two hours, but not after one week (Fig. 2).

Among the most common taxa, the abundances of Baetis and Tanypodinae did not vary with any of the studied factors. The abundance of Leptophlebiidae varied with the interaction cobble texture $\mathrm{x}$ current velocity at the second sampling moment $(\mathrm{F} 2,16=4.84$, $\mathrm{p}=0.0226$ ). Leptophlebiids seem to be higher in patches with smooth cobbles (Fig. 3). The abundance of Leuctra varied with time of colonization $\left(\mathrm{F}_{1,16}=\right.$ $5.92, \mathrm{p}=0.0271)$, and the interactions time of coloni-
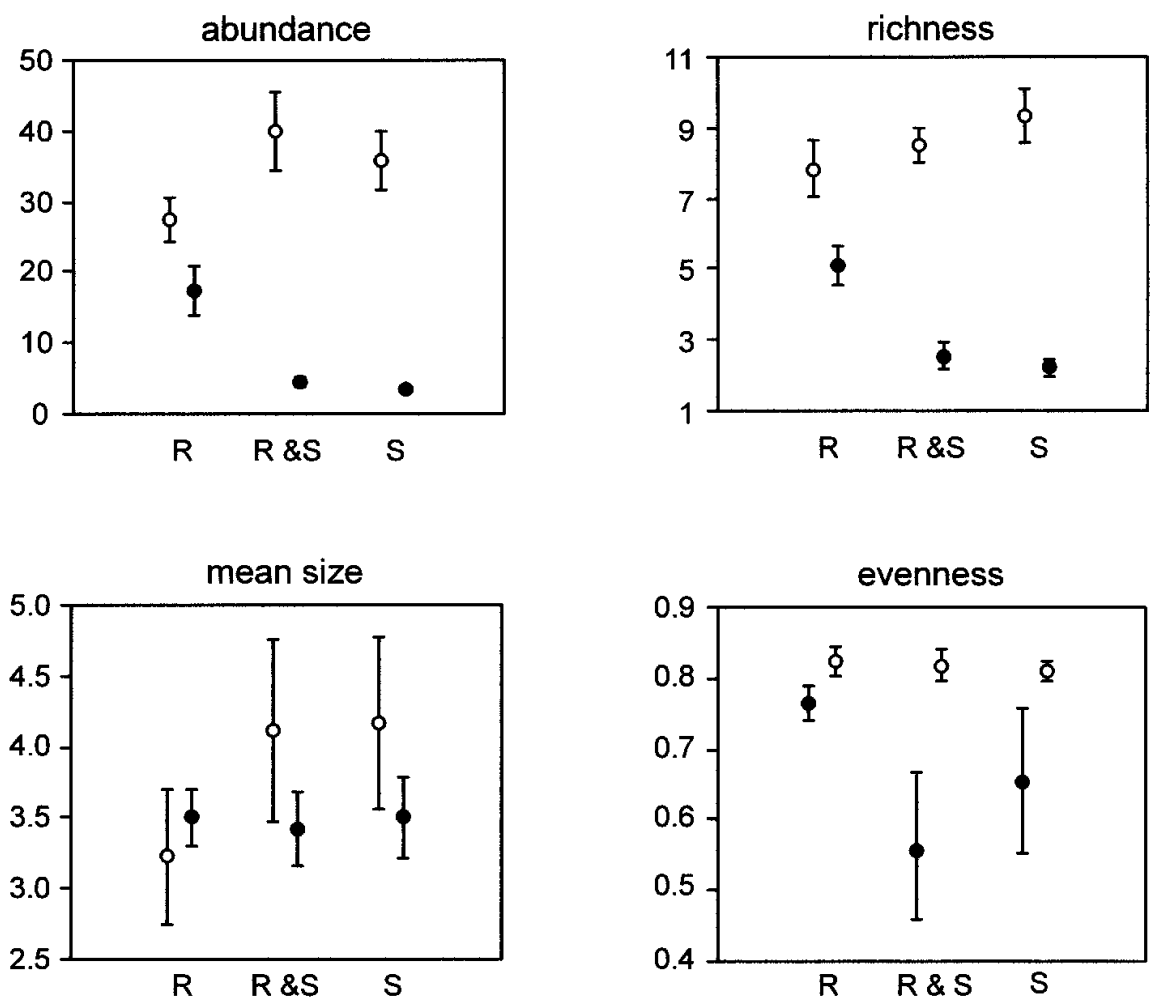

- two hours

o one week

Fig. 2. Average (error bars = SE) macroinvertebrate abundance, taxa richness, mean body size, and community evenness, at the two stages of colonization (two hours and one week), in patches with two rough cobbles $(\mathrm{R})$, one rough and one smooth cobble (R\&S), and two smooth cobbles $(\mathrm{S})$. For mean body size, gravel rather than cobble texture is shown. 
zation $\mathrm{x}$ gravel texture $\left(\mathrm{F}_{2,16}=4.56, \mathrm{p}=0.0272\right)$ and time of colonization $\mathrm{x}$ gravel texture $\mathrm{x}$ cobble area $\left(F_{2,16}=5.82, p=0.0126\right)$. Leuctra seems to be higher in patches with smooth gravel after one week. The abundance of Orthocladiinae varied with the interactions time of colonization $x$ cobble texture $\left(\mathrm{F}_{2,16}=\right.$ $5.88, \mathrm{p}=0.0121)$ and time of colonization $\mathrm{x}$ cobble texture $x$ cobble surface area $\left(\mathrm{F}_{2,16}=5.95, \mathrm{p}=0.0117\right)$. The Orthocladiinae seem to be higher in patches with rough cobbles after two hours, and the opposite after one week (Fig. 3).

Among the functional feeding groups, only the relative abundance of scrapers showed variation, and this variation occurred with water depth $\left(\mathrm{F}_{1,16}=9.91\right.$, $\mathrm{p}=0.0062)$ and the interactions cobble texture $\mathrm{x}$ current velocity at the first sampling moment $\left(\mathrm{F}_{2,16}=\right.$ $5.88, \mathrm{p}=0.0122$ ) and time of colonization $\mathrm{x}$ cobble texture $\mathrm{x}$ current velocity at the first sampling moment $\left(F_{2,16}=4.02, p=0.0385\right)$. The relative abundance of scrapers seems to be lower in patches with smooth cobbles after two hours, and higher in patches with rough cobbles after one week (Fig. 3).

\section{Discussion}

The results of this study suggest that substrate colonization by stream macroinvertebrates is influenced by surface texture of cobbles, but also indicate that this relationship is complex and depends on the time of colonization, together with the local environmental conditions (at least the current velocity during the colonization, and the surface area of the cobbles that are being colonized). The number of individuals and taxa colonizing a denuded substrate, as well as the evenness of the community, seem to be more influenced by cobble texture after two hours than after one week of colonization, being more abundant on rough substrates. Downes et al. (2000) also found that rough substrates were colonized by more taxa than smooth substrates, in an experiment with both natural and artificial substrates. Additionally, when they examined reference (natural) substrates, rough cobbles supported both more individuals and more taxa than smooth cobbles (Downes et al. 2000). The positive effect of substrate complexity on macroinvertebrate abundance or taxa richness is not exclusive to mineral substrates, as it has been found with wood (O'Connor 1991) and macrophytes (Jeffries 1993).

It seems that taxa are differentially affected by substrate texture. In this study, texture had no effect on the abundance of Baetis and Tanypodinae, but influenced the abundance of Leptophlebiidae, Leuctra and Ortho- cladiinae. In addition, the effect of substrate texture seems to differ between functional feeding groups. In this study, texture only affected the relative abundance of scrapers, which were more abundant in patches with rough cobbles after a week of colonization. This relationship could be mediated by the development of an epilithic layer, which seems to develop faster on rough than on smooth surfaces (Sanson et al. 1995). However, it is difficult to separate the effect of substrate texture itself from the effect of the associated food resources (Mackay 1992), and this difficulty has precluded the examination of these two factors independently in most studies (Downes et al. 1998). In some cases, it has been found that the abundance of epilithon, rather than substrate texture, is of importance for macroinvertebrate distribution (Gawne \& Lake 1995). In this study, the effect of epilithon was minimized as much as possible by selecting substrate particles that had been dry for some weeks, and thus free of an epilithon layer. This procedure is similar to acid-scouring (Mackay 1992) and provides substrates that at first offer only attachment sites and shelter for colonizers rather than food resources. It has also been shown that epilithic growth is slower on acid-scoured stones than on stones that have been only brushed, but colonization patterns by macroinvertebrates are still similar on both kinds of stones (Boulton et al. 1988). Although the amount of epilithon was not quantified in this stu$\mathrm{dy}$, the results suggest that after one week of colonization, the epilithon may have begun colonizing rough cobbles more abundantly than smooth ones, and this could make the relative abundance of scrapers higher on patches with rough cobbles. However, the effect of substrate texture on total abundance, richness and evenness occurs after two hours but not after one week of colonization, so this effect could be independent of the development of the epilithic layer.

Some studies have considered other kinds of substrate complexity at scales significant for macroinvertebrates, like the presence of grooves and pits, or the complexity of particle shape (e.g. Hart 1978, Downes \& Jordan 1993, Way et al. 1995). Grooves and pits may serve as refuge from certain predators, and may create a favorable flow microenvironment. For example, some hydropsychids construct their nets preferentially within pits than on flat surfaces (Downes \& Jordan 1993). Macroinvertebrate densities have been found to be greater on grooved (artificial) substrates than on smooth and rough substrates (Way et al. 1995). The complexity of particle shape affects taxon richness, which is greater on more complex shapes (Hart 1978). These different sources of substrate complexity 
differ in spatial scale $\left(10^{-4}\right.$ to $10^{-3} \mathrm{~m}$ for surface texture, $10^{-3}$ to $10^{-2} \mathrm{~m}$ for grooves and pits, and $10^{-2}$ to $10^{-1} \mathrm{~m}$ for complexity of particle shape) and, although in all cases they can be detected by macroinvertebrates, their response to each kind of complexity may depend on their own body size. For example, it seems that roughness affects smaller individuals more than do large crevices (Downes et al. 1998), and results from this study support this relationship, given that mean body size was lower in rough substrates after a week of colonization. This phenomenon has also been observed on macrophytes, where more complex shapes offer much more small-scale habitat, thus supporting disproportionately more small fauna (Jeff $\mathrm{r}$ i e s
1993). Mechanisms responsible for all these relationships, however, are still unknown.

Short-term colonization experiments have been sometimes considered unrealistic (Mackay 1992). However, macroinvertebrate densities have been found to stabilize even in two days (Ciborowski \& Cliff o r d 1984), and taxa richness can reach equilibrium in six (Townsend \& Hildrew 1976) or eight days (Doeg et al. 1989). Given the high resilience of macroinvertebrate communities, colonization of denuded substrates begins immediately after the disturbance event, when the intensity of the disturbance allows the presence of surrounding colonists (Boyero \& DeLope 2002). Thus, short-term colonization experiments cannot be descri-
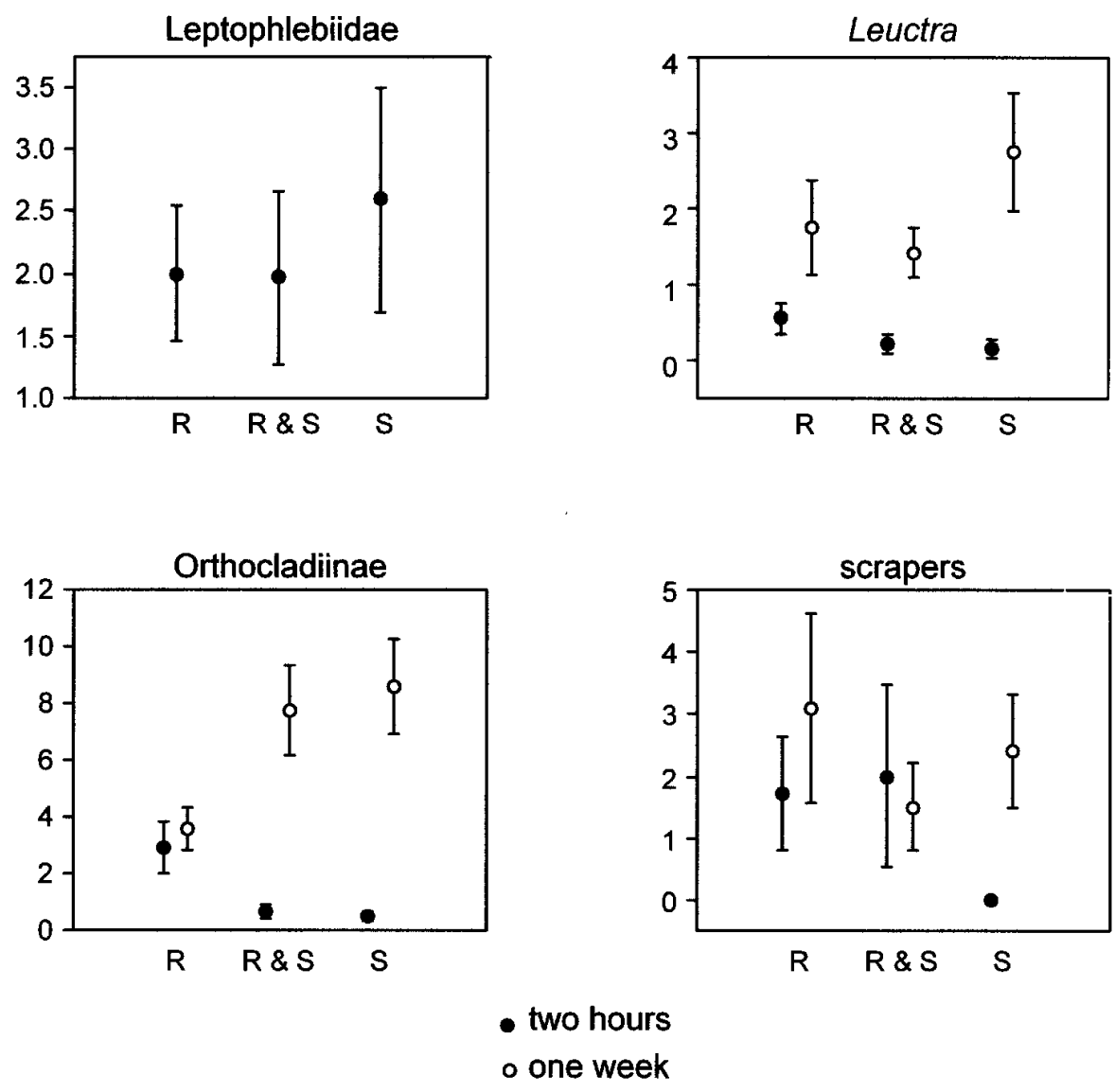

Fig. 3. Average abundances (error bars $=\mathrm{SE}$ ) of Leptophlebiidae, Leuctra and Orthocladiinae, and relative abundace of scrapers, at the two stages of colonization (two hours and one week), in patches with two rough cobbles $(\mathrm{R})$, one rough and one smooth cobble (R\&S), and two smooth cobbles (S). For the abundance of Leuctra, gravel rather than cobble texture is shown; for the abundance of Leptophlebiidae, the two stages of colonization were not separated, because time of colonization did not interact with cobble texture. 
bed as unrealistic, although we must be conscious of the temporal and spatial scales of each experiment.

In summary, these data provide evidence that substrate texture has an effect on macroinvertebrate colonization, but it also suggests that this effect is complex and depends on the time of colonization and the local environment. It is possible that substrate texture simply modulates the effect of more important factors, such as current velocity or time of colonization. Other substrate characteristics known to affect their colonization are size and shape, and even colour (Love \& Bailey 1992), but the interaction between these characteristics and substrate texture is unknown. In order to understand the role of substrate complexity on colonization, it would be necessary to perform more complex experiments, in which the different types of complexity (texture, presence of pits and grooves, and complexity of particle shape), the levels of different food resources, and environmental factors such as current velocity and the surface area of substrate particles, are manipulated.

\section{Acknowledgements}

J. Bosch helped with the experimental design, fieldwork, and figures. J. Bosch and P. Rincón provided helpful comments on the manuscript. A. García-Valdecasas contributed to the theoretical development of this work. J. Vielva (director of the Parque Natural de Peñalara) and the Consejería de Medio Ambiente of the Comunidad de Madrid provided permits for fieldwork. The author was supported by a predoctoral fellowship from the Comunidad de Madrid (Spain), cofinanced by the European Social Fund, during the study, and by a postdoctoral fellowship from the Ministerio de Educación y Cultura (Spain), during writing of the manuscript . Partial funding was obtained from the projects 07M/0125/2000 (Comunidad de Madrid) and REN2000-2040 GLO (MCYT), Spain (PI: A.I. Camacho)

\section{References}

Boulton A.J., Spangaro G.M. \& Lake P.S. 1988. - Macroinvertebrate distribution and recolonization on stones subjected to varying degrees of disturbance: an experimental approach. Arch. Hydrobiol., 113 : 551-576.

Boyero L. \& DeLope J.L. 2002. - Short term recolonization of stones in a tropical, island stream. Mar. Freshwat. Res., 53 : 993998.

Ciborowski J.J.H. \& Clifford H.F. 1984. - Short term colonization patterns of lotic macroinvertebrates. Can. J. Fish. Aquat. Sci., 41: 1626-1633.

Cooper S.D., Barmuta L., Sarnelle O., Kratz K. \& Diehl S. 1997. Quantifying spatial heterogeneity in streams. J. N. Am. Benthol. Soc., $16: 174-188$.

Doeg T.J. \& Lake P.S. 1981. - A technique for assessing the composition and density of the macroinvertebrate fauna of larg e stones. Hydrobiologia, $80: 3-6$.
Doeg T.J., Lake P.S. \& Marchant R. 1989. - Colonization of experimentally disturbed patches by stream macroinvertebrates in the Acheron River, Victoria. Aust. J. Ecol., 14 : 207-220.

Downes B.J. \& Jordan J. 1993. - Effects of stone topography on abundance of net-building caddisfly larvae and arthropod diversity in an upland stream. Hydrobiologia, $252: 163-174$.

Downes B.J., Lake P.S., Schreiber E.S.G. \& Glaister A. 1998. - Habitat structure and regulation of local species diversity in a stony, upland stream. Ecol. Monogr., 68 : 237-257.

Downes B.J., Lake P.S., Schreiber E.S.G. \& Glaister A. 2000. Habitat structure, resources and diversity : the separate effects of surface roughness and macroalgae on stream substrates. Oecolo gia, $123: 569-581$.

Gawne B. \& Lake P.S. 1995. — Effects of microspatial complexity on a herbivore-epilithon interaction in an Australian upland stream. Freshwat. Biol., 33 : 557-565.

Hart D.D. 1978. —Diversity in stream insects: regulation by rock size and microspatial complexity. Ve rh. Int. Ve rein. Limnol., 20 : $1376-1381$

Jeffries M. 1993. - Invertebrate colonization of artificial pondweeds of differing fractal dimension. Oikos, $67:$ 142-148.

Love S.D. \& Bailey R.C. 1992. - Community development of epilithic invertebrates in streams: independent and interactive effects of substratum properties. Can. J. Zool., 70 : 1976-1983.

Mackay R.J. 1992. — Colonization by lotic macroinvertebrates: a review of processes and patterns. Can. J. Fish. Aquat. Sci., 49 : 617-628.

Magurran A.E. 1988. - Ecological diversity and its measurement. Princeton University Press, Princeton, $179 \mathrm{p}$.

Merritt R.W. \& Cummins K.W. 1996. - An introduction to the aquatic insects of North America. Kendall/Hunt, Dubuque, 862 p.

Minshall G.W. 1984. - Aquatic insect-substratum relationships. Pages 358-400 in The Ecology of Aquatic Insects. Resh V.H. \& Rosenberg D.M. (eds). Praeger Scientific, New York.

O'Connor N.A. 1991. - The effects of habitat complexity on the macroinvertebrates colosining wood substrates in a lowland stream. Oecologia, 85 : 504-512.

Robson B.J. \& Barmuta L.A. 1998. - The effect of two scales of habitat architecture on benthic grazing in a river. F reshwat. Biol., 39: $207-220$

Sanson G.D., Stolk R. \& Downes B.J. 1995. - A new method for characterizing surface roughness and available space in biological systems. Funct. Ecol., 9 : 127-135.

Tachet T., Richoux P., Bournaud M. \& Usseglio-Polatera P. 2002. Invertébrés d'eau douce. Systématique, biologie, écologie. CNRS Editions, Paris, 587 p.

Townsend C.R. \& Hildrew A.G. 1976. — Field experiments on the drifting, colonization and continuous redistribution of stream benthos. J. Anim. Ecol., 45: 759-772.

Vinson M.R. \& Hawkins C.P. 1998. - Biodiversity of stream insects: variation at local, basin and regional scales. Ann. Rev. Ento mol., $43: 271-293$.

Wallace J.B. \& Webster J.R. 1996. - The role of macroinvertebrates in stream ecosystem function. Ann. Rev. Entomol., 41 : 115139.

Way C.M., Burky A.J., Bingham C.R. \& Miller A.C. 1995. — Substrate roughness, velocity refuges and macroinvertebrate abundance on artificial substrates in the lower Mississippi River. J. N. Am. Benthol. Soc., 14 : 510-518. 